\title{
Impact of the Digital Economy on Intellectual Performance Russian Regions
}

\author{
Vlasov M. ${ }^{1,2}$ \\ ${ }^{1}$ Institute of Economics of the Ural Branch of the RAS, Ekaterinburg, Russia \\ ${ }^{2}$ Ural Federal University named after the First President of Russia B.N. Yeltsin, Ekaterinburg, Russia \\ Email:
}

\begin{abstract}
The article delves into the problems of the influence of digital technologies on intellectual performance. The relevance of the study is due to the fact that digital platforms underpin the innovative management mechanisms marked with a growing share of automation processes in the field of generation of knowledge and intellectual activity. One of such problems is the lack of unified methodological approaches to assessing the impact of digital technologies on intellectual performance. The methodological basis of the study includes strategic management theory and the principles of public and municipal governance. The research method is correlation analysis of the indicators of intellectual activity and the indicators of digital resources application. The information base of the research includes data on digital technologies application and the number of intellectual deliverables retrieved from the official website of the Federal State Statistics Service for the period of 2015-2017. Based on the theoretical analysis carried out, the authors conclude that the results of intellectual activity are the main tool for developing economic entities. We develop the weighted correlation coefficient of intellectual performance. This is an indicator that contains estimates of correlation coefficients of the results of intellectual activity and digital technologies, each of which has its own weighted coefficient. The study proves that digital technologies affect intellectual performance and their application increases the efficiency of intellectual activity.
\end{abstract}

Keywords: intellectual activity, digital technologies, correlation coefficient, digital society management, regional development

\section{INTRODUCTION}

The application of digital technologies in the various spheres of activity in society is due to the emergence of the knowledge economy that has become the central trend in the global development. The primary purpose of the continued evolution of the knowledge economy is to address the problem of managing the progress of scientific activity under the influence of digital technologies. Digital platforms underpin the innovative management mechanisms marked with a growing share of automation processes in the field of generation of knowledge and intellectual activity per se. Hence, it is extremely relevant for economics to design and evaluate measures on enhancing intellectual performance driven by the application of digital technologies.

The purpose of the current research is to assess the influence of digital technologies on intellectual performance in Russian regions.

The logic of the paper embraces the following steps. Having reviewed the previous studies, we formulate the working hypotheses about the effect of digital technologies on intellectual performance. Then, within the framework of the research procedure, we determine the apparatus for assessing the dependencies of intellectual deliverables on the use of digital technologies. Lastly, we perform an empirical evaluation of these relationships using the case studies of Russian districts and analyze the obtained data.

\section{INTERCONNECTION BETWEEN INTELLECTUAL ACTIVITY AND DIGITAL TECHNOLOGIES}

\begin{abstract}
Currently, intellectual capital and processes of knowledge management have a dramatic impact on the effectiveness of strategical and tactical processes in day-to-day operations of manufacturing companies.

The knowledge economy era is the one driven by innovation, mainly based on the contribution of intangible assets which play a decisive role in the long-term development of enterprises. The cost of products manufactured by enterprises is largely dependent on their intellectual capital. The enterprises, therefore, have to strengthen their investment in intellectual capital, and, in order to be competitive in the market, they have to share the knowledge with the rest of the networks' participants. According to Li et al. [2019], intellectual capital not only
\end{abstract}


exerts a direct positive influence on the innovation activities of enterprises, but also supports their innovation activities through knowledge sharing.

As global experience shows, it is only possible to maintain stable economic growth by using innovation as its basis and actively applying contemporary scientific and technological achievements. It this case, there is an increase in the chances for high quality growth, resource saving, production efficiency, and production of competitive goods in the domestic and global markets. At that, the innovation basis of economic development is comprised of the results of intellectual activity, and increasing intellectual performance is the fundamental task for economic agents at all levels of business activity [Tlesova et al., 2018].

As Subramanian and van de Vrande [2019] put it, the three essential aspects of intellectual capital - human, structural, and social - are designed to improve the efficiency of new product offerings. The findings reported by Nadeem, Dumay and Massaro [2019] indicate that there is a significant positive relationship between intellectual capital and its components (human, innovation and physical capitals) and firm performance. Soetanto and Liem [2019] consider intellectual capital as a valuable asset in creating a company's wealth and ensuring its sustainability. The research results illustrate that intellectual capital has a significant and positive effect on firm performance.

The study by Gârdan et al. [2018] is based on a qualitative research methodology in the form of an in-depth survey. The research paper emphasizes that companies that develop a sustainable knowledge management system integrated into their marketing strategy occupy the most a prominent place in the market and enjoy numerous competitive advantages. For innovation business models, knowledge is a valuable asset suitable for capitalizing on it.

The purpose of the study by Dabić et al. [2019] is to analyze the relationship between the three components of intellectual capital (human, structural, and relational) and their influence on business performance. Based on a survey of 253 enterprises in Croatia, the researchers find that the key dimensions of intellectual capital are vital to a company's success and are strongly inter-correlated. Realizing the role of intellectual capital and innovative culture in relation to doing business, especially in the countries with transitional economies, can have considerable implications for executives and business owners, as well as managers and academics.

According to Zhang, Lettice and Pawar [2019], intellectual capital underlies the crucial methods of knowledge management in order to introduce innovations and increase their performance. Lui, Li and Chu [2019] conclude that companies engaged in generation and accumulation of knowledge are characterized by higher business performance in comparison with other organizations.

Kengatharan [2019] examines the relationship between intellectual capital, productivity and firm performance. The researcher proves that intellectual capital is among the main factors in raising productivity of business entities.
The results also indicate that there is a positive relationship between productivity and company performance.

Al-Tal and Emeagwali [2019] position knowledge management and intellectual capital as the key determinants for competitiveness, productiveness and organizational performance of business. Moreover, intellectual capital acts as a powerful predictive factor in terms of innovation in the field of business activities.

Buenechea-Elberdin, Kianto and Sáenz [2018] treat firm technology level and innovation type as contingency variables. The researchers argue that because high-tech and low-tech firms differ in terms of several knowledge features (complexity, tacitness and pace of renovation), it is likely that their innovation performance is supported by different combinations of intellectual capital components. In addition, differences between innovation in the field of product/service and in management can also cause changes in the degree of relevance of various components of intellectual capital. At that, the development of intellectual capital serves as the basis for innovation development of businesses.

Duodu and Rowlinson [2019] hypothesize that intellectual capital is a means by which firms increase their potential and develop capabilities that enhance competitive advantage. The study confirms the hypothesis and demonstrates a direct relationship between intellectual capital and exploratory and exploitative innovation of a firm. According to Cho, Kirkewoog and Daim [2018], the strategic use of intellectual capital is crucial for technology-based companies to gain competitive advantage.

Digital technologies have significantly increased working pace in the modern world. Internet and digital devices drive economic growth [Afonasova et al., 2019]. The advent of brand-new and powerful digital technologies, digital platforms and digital infrastructures has remarkably transformed innovation and entrepreneurship. Digital technologies open up new opportunities not only for innovators and entrepreneurs, but also for researchers in all fields of scientific knowledge [Nambisan, Wright, Feldman, 2019]. However, there are no research studies on how digital technologies influence intellectual performance, which is the basis of innovation.

Gupta, Mejia and Kajikawa [2019] claim that the development of digital ecosystems has a far-reaching effect on the evolution of innovation ecosystems, thereby developing the body of knowledge, both in academia and industry. Nevertheless, this study is limited only by indirect data; there are no quantitative assessments of the impact of digital technologies on the development of new knowledge.

Kayley [2017] highlights that the application of digital technologies can contribute to the intellectual development and enhance the effectiveness of intellectual activity. Accelerated introduction and expansion of digital economy, as well as the national information infrastructure, improve modern intellectual capital in all areas of social life [Melnyk et al., 2018].

As emphasized by Urbinati et al. [2019], digital technologies create lots of new products and services. The 
authors find that a significant share of modern intellectual capital and related innovation options for diffusing new products and services are ensured by digital technologies. In a knowledge-based economy, the processes that unfold to perform tasks and make decisions are of special importance. The automation of these processes will assist in boosting the efficiency of new knowledge generation. Hence, digital technologies improve the performance of scholarly activities [Sung et al., 2012].

Empirical evidence indicates that companies that introduce and proactively apply digital technologies and Industry 4.0 technologies obtain greater benefits fromlearning and knowledge sharing at an organization level, and as a result they demonstrate higher rates of intellectual capital development [Tortorella et al., 2020].

Digital technologies are able to facilitate knowledge flows and exchange, thereby accelerating the generation of new knowledge and increasing the level of intellectual capital of a firm [Forman, van Zeebroeck, 2019].

Ravarini, Locoro and Martinez [2020] state that, although modern research publications discuss numerous models of economic evaluation of digital technologies, there are still no theoretical propositions on how to model and evaluate the impact of digital technologies on knowledge generation processes and the development of intellectual capital.

Having reviewed the previous studies, we arrive at the following conclusions.

The overwhelming majority of researchers around the world admit that the results of intellectual activity are the main tool for economic development of firms. Economists from different countries have proven the importance of applying digital technologies to improve the results of research activities. However, economic literature lacks the assessment of the influence of digital technologies on intellectual performance.

Based on the results of previous studies, we put forward the following working hypotheses:

1) digital technologies allow enhancing the performance of intellectual activity;

2) the extent to which digital technologies affect intellectual performance varies depending on Russia's region.

\section{RESEARCH METHOD}

To demonstrate the importance of digital technologies influence on intellectual performance, we analyze the indicators of digital technologies (the number of personal computers per 100 employees; the number of active mobile subscribers per 1,000 population; the number of active users of fixedline and mobile internet; the share of companies using CRM systems; and the share of organizations using electronic document management systems) and the indicators of intellectual performance (the number of patent applications filed; the number of patent applications approved (patents granted); the number of inventions in use; the number of advanced technologies developed; and the number of utility models created). The mentioned digital technologies are selected due to the fact that they are the only ones considered by the Federal State Statistics Service when keeping statistical records; data on other digital technologies are not available.

Data on the level of digital technologies application and the number of intellectual deliverables for the period from 2015 to 2017 (the latest data at the time of the study) are retrieved from the official website of the Federal State Statistics Service.

The methodological framework of the research is strategic management theory, the principles of public and municipal governance, as well as theoretical and practical foundation of regional governance. The research methods include common procedures of collecting, processing and analyzing economic evidence, modelling knowledge increment processes, and methods of economic sociology and statistics.

To establish the relationships between digital technologies and results of research activities, we conduct correlation analysis and determine the connection between the amount of each type of digital resources and the outcome of knowledge generation in regional economic systems.

Correlation analysis allows us to identify the relationships between data series and resolve the following problems: searching and recognizing the factors that have the maximum effect on the attribute under study by measuring the level of correlation between them, as well as detecting previously unexplored causal relationships.

Data of correlation analysis are explained using the Chaddock scale [Ishkhanyan, Karpenko, 2016]. The interpretation of the correlation coefficient is as follows:

- more than 0.75 , the relationship between parameters is stable and developed;

- from 0.5 to 0.75 , the relationship is variable and unstable;

- from 0.25 to 0.5 , the relationship is partial and unstable;

- less than 0.25 , there is no relationship.

The research objects are the federal districts of the Russian Federation that differ in the level of intellectual activity and the level of digital technologies introduction.

It is worth noting that paired correlations of the five indicators of intellectual activity development and the five indicators of digital technologies introduction for eight federal districts produce 200 quantitative estimates that are difficult to interpret scientifically. Therefore, to reveal the dependencies between the influence of digital technologies and intellectual performance, the authors apply the weighted correlation coefficient.

The weighted correlation coefficient of intellectual performance is an indicator that contains estimates of the correlation coefficients of intellectual performance and digital technologies, each of which has its own weighted coefficient.

The general formula for this indicator is the following:

$$
K_{j}=\sum_{j=1}^{n} a_{j} \times x_{j}
$$

where $\mathrm{Kj}$ denotes the weighted correlation coefficient of a type of intellectual performance with $\mathrm{j}$-th set of digital 
districts also exhibit a positive unsteady relationship. Thus, we can conclude that the development of digital technologies allows improving intellectual performance in the field of designing new inventions.

Figure 2 illustrates the weighted correlation coefficients of such an intellectual deliverable as "The number of patent applications approved" and digital technologies in the federal districts of the Russian Federation.

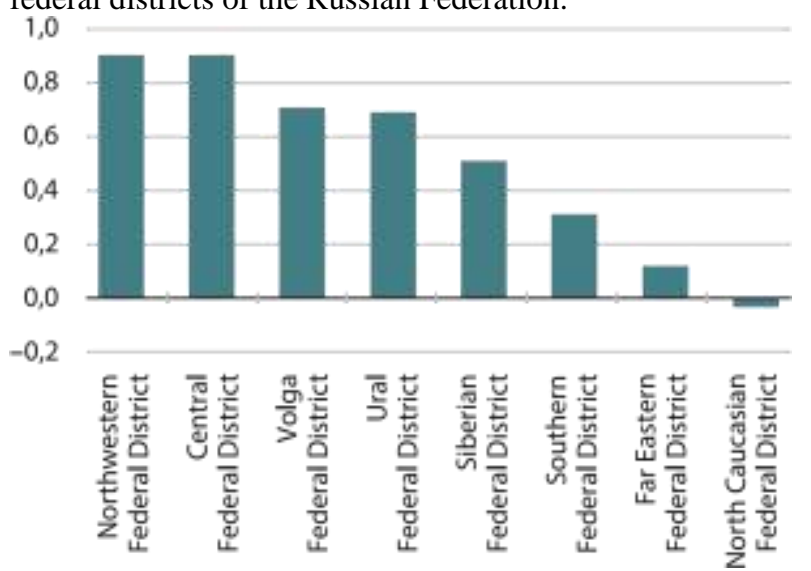

Figure 2 Weighted correlation coefficient of the intellectual deliverable "The number of patents applications approved" and digital technologies in the federal districts of the Russian Federation

The obtained results are presented in the form of bar charts indicating the dependences of the weighted correlation coefficients between intellectual performance and digital resources applied.

Figure 1 shows the weighted correlation coefficients of such an intellectual deliverable as "The number of patent applications filed for inventions" and digital technologies in the federal districts of the Russian Federation.

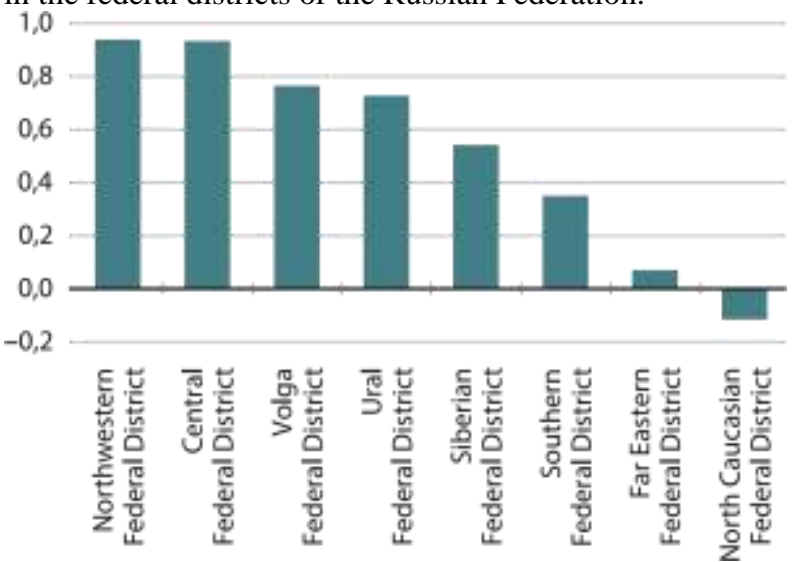

Figure 1 Weighted correlation coefficient of the intellectual deliverable "The number of patent applications filed" and digital technologies in the federal districts of the Russian Federation

The analysis of the results shown in Fig. 1 reveals that there is a pronounced relationship between the intellectual deliverable "The number of patent applications filed" and digital technologies. At the same time, a steady influence of digital technologies on this intellectual deliverable is observed in five out of eight federal districts. Two more
Digital technologies also serve as a tool for stimulating the intellectual deliverable "The number of patents applications approved". In five out of eight federal districts, there is a stable positive relationship between digital technologies and this intellectual deliverable. Analysis of Fig. 1 and Fig. 2 indicates that digital technologies exert a powerful effect on the entire cycle of inventive activities, starting from designing an invention to getting a patent.

Figure 3 presents the weighted correlation coefficients of such an intellectual deliverable as "The number of inventions in use" and digital technologies in the federal districts of the Russian Federation.

As indicated in Figure 3, digital technologies ensure more productive use of inventions by companies. The obtained result is due to the fact that digital technologies allow optimizing the transfer and exchange of data, which makes the details on new inventions publicly available. Hence, analysis of Figures 1-3 proves that digital technologies are the main driver for creating new inventions and introducing them into business activity of companies, which positively affects the socio-economic development of Russia's regions. 


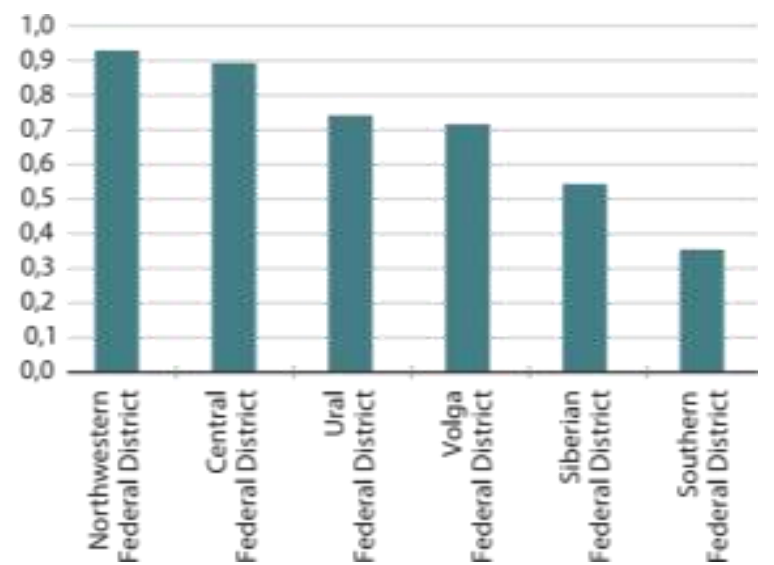

Figure 3 Weighted correlation coefficient of the intellectual deliverable "The number of inventions in use" and digital technologies in the federal districts of the Russian Federation (no data available for the Far Eastern and North Caucasian Federal Districts)

Figure 4 shows the weighted correlation coefficients of such an intellectual deliverable as "The number of advanced technologies developed" and digital technologies in the federal districts of the Russian Federation.

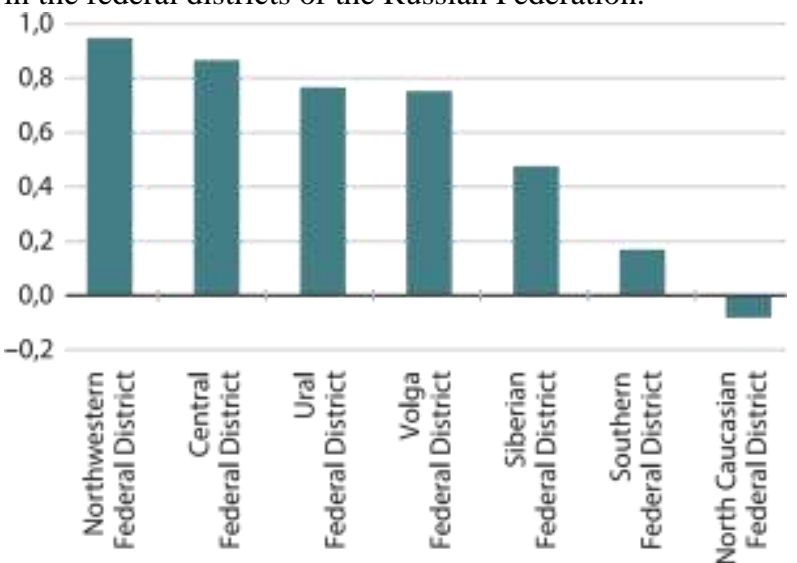

Figure 4 Weighted correlation coefficient of the intellectual deliverable "The number of advanced technologies developed" and digital technologies in the federal districts of the Russian Federation (no data available for the Far Eastern Federal District)

Figure 4 displays a stable relationship between digital technologies and the intellectual deliverable "The number of advanced technologies developed". We can assume that digital technologies allow improving intellectual performance. An increase in the use of digital technologies leads to an increase in the number of advanced technologies developed.

Figure 5 illustrates the weighted correlation coefficients of such an intellectual deliverable as "The number of utility models created" and digital technologies in the federal districts of the Russian Federation.

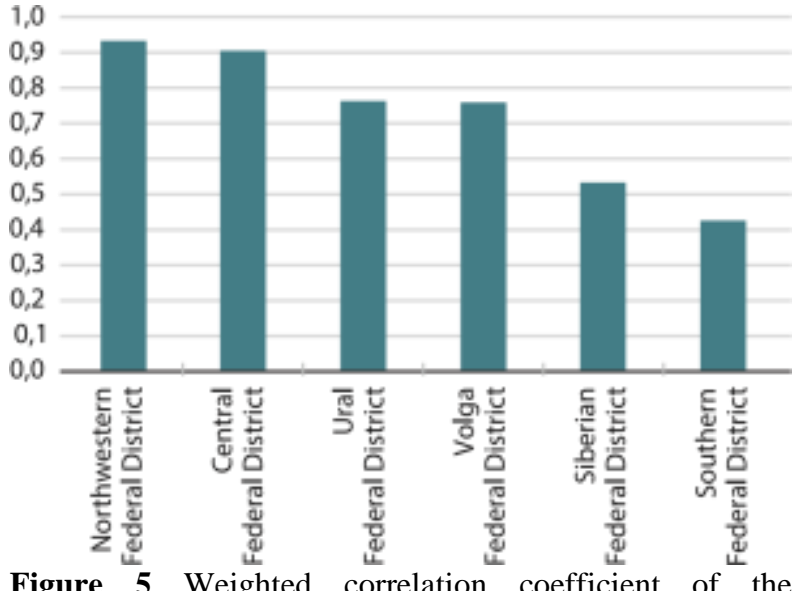

Figure 5 Weighted correlation coefficient of the intellectual deliverable "The number of utility models created" and digital technologies in the federal districts of the Russian Federation (no data available for the Far Eastern and North Caucasian Federal Districts)

Analysis of data presented in Fig. 5 shows that digital technologies have a stable positive influence on the intellectual deliverable "The number of utility models created". The application of digital technologies makes it possible to enhance the effectiveness of companies' activities in creating utility models.

The second hypothesis of the research has also been completely confirmed. There are leading regions that exhibit a strong correlation between digital technologies and intellectual performance, and outsider regions, where there is practically no correlation between digital technologies and intellectual performance.

\section{DISCUSSION}

To discuss the research results, we introduce ranking scores according to the obtained correlation coefficients between the indicators of intellectual activity and the application of digital resources based on the generally accepted interpretation of the numerical values of paired correlation coefficients:

- stable relationship - score 1 ;

- unstable relationship - score 2;

- partial relationship between parameters - score 3;

- no relationship - score 4.

In this case, the results can be displayed in tabular format. To compare the regions, we use the four indicators of intellectual activity: the number of patent applications approved; the number of inventions in use; the number of advanced technologies developed; and the number of utility models created. Table 2 presents the obtained ranking scores of the federal districts. 
enduring economic development of business entities. Economists from around the world have proven the importance of applying digital technologies to improve the results of research activities. However, the modern economic literature lacks the assessment of the influence of digital technologies on intellectual performance.

Secondly, the authors of the given paper propose the weighted correlation coefficient for intellectual performance. This is an indicator that contains estimates of correlation coefficients of the intellectual deliverables and digital technologies.

Thirdly, the research proves that digital technologies have a stable relationship with intellectual performance.

The application of digital technologies increases the effectiveness of intellectual performance.

Fourthly, different regions are characterized by different degree of closeness of the relationship between digital technologies and intellectual activity. In this context, it is necessary to transfer the leading regions' norms and experience in the field of digital technologies application to the outsider regions.

Fifthly, the study performs the ranking of the Russian regions by revealing the relationship between intellectual performance and the application of advanced information resources.

Theoretical significance of the research is to reveal the relationship between the technologies of digital economy and intellectual performance, which is the basis for further studies on improving the effectiveness of scientific activity through the use of digital technologies.

Practical importance of the research is to determine the weighted coefficients of digital technologies that influence intellectual performance, which can be used to plan the directions for increasing the effectiveness of scientific activities.

\section{ACKNOWLEDGMENT}

The article has been prepared in accordance with the state assignment for the Institute of Economics of Ural Branch of RAS for 2020.

\section{REFERENCES}

[1] Ishkhanyan M.V., Karpenko N.V. (2016). Ekonometrika. Chast' 1. Parnaya regressiya. Moscow: MGUPS (MIIT) Publ.

[2] Vlasov M.V., Panikarova S.V. (2019). Analysis of institutions of knowledge generation of a smart city in conditions of digital economy. Journal of Chelyabinsk State University. № 7 (429). pp. 49-59.

[3] Afonasova M.A., Panfilova E.E., Galichkina M.A., Ślusarczyk B. (2019). Digitalization in economy and innovation: The effect on social and economic 
[12] Kayley P. (2017). Interpersonal relationships as key drivers of cluster performance. Proceedings of the European Conference on Innovation and Entrepreneurship ECIE, vol. 2017, pp. 362-367.

[13] Kengatharan N. (2019). A knowledge-based theory of the firm: Nexus of intellectual capital, productivity and firms' performance. International Journal of Manpower, vol. 40, no. 6, pp. 1056-1074. DOI: 10.1108/IJM-03-2018-0096.

[5] Buenechea-Elberdin M., Kianto A., Sáenz J. (2018). Intellectual capital drivers of product and managerial innovation in hightech and low-tech firms. R \& D Management, vol. 48, no. 3. pp. 290-307. DOI: https://doi.org/10.1111/radm.12271.

[6] Cho Y., Kirkewoog S., Daim T.U. (2018). Managing strategic intellectual property assets in the fuzzy front end of new product development process. R \& D Management, vol. 48, no. 3, pp. 354-374. DOI: https://doi.org/10.1111/radm.12312.

[7] Dabić M., Lažnjak J., Smallbone D., Švarc J. (2019). Intellectual capital, organisational climate, innovation culture, and SME performance: Evidence from Croatia. Journal of Small Business and Enterprise Development, vol. 26, no. 4, pp. 522-544. DOI: https://doi.org/10.1108/JSBED-04-2018-0117.

[8] Duodu B., Rowlinson S. (2019). Intellectual capital for exploratory and exploitative innovation: Exploring linear and quadratic effects in construction contractor firms. Journal of Intellectual Capital, vol. 20, no. 3, pp. 382-405. DOI: http://dx.doi. org/10.1108/JIC-08-20180144.

[9] Forman C., van Zeebroeck N. (2019). Digital technology adoption and knowledge flows within firms: Can the Internet overcome geographic and technological distance? Research Policy, vol. 48, no. 8, pp. 1-1. DOI: 10.1016/j.respol.2018.10.021.

[10] Gârdan D.A., Andronie M., Gârdan I.P., Andronie I.E., Iatagan M., Hurloiu I. (2018). Bioeconomy development and using of intellectual capital for the creation of competitive advantages by SMEs in the field of biotechnology. Amfiteatru Economics, vol. 20, no. 49, pp. 647-666. DOI: http://dx.doi.org/10.24818/EA/2018/49/647.

[11] Gupta R., Mejia C., Kajikawa Y. (2019). Business, innovation and digital ecosystems landscape survey and knowledge cross sharing. Technological Forecasting and Social Change, vol. 147(C), pp. 100-109. DOI: 10.1016/j.techfore.2019.07.004.
[14] Li Y., Song Y., Wang J., Li C. (2019). Intellectual capital, knowledge sharing, and innovation performance: Evidence from the Chinese Construction Industry. Sustainability (Switzerland), vol. 11, no. 9, pp. 1-20. DOI: 10.3390/su11092713.

[15] Lui T.T.S., Li Z., Chu S.K.W. (2019). Achieving business performance via implementation of knowledge management: A comparative study of MAKE and nonMAKE companies. International Journal of Knowledge Management, vol. 15, no. 4, pp. 1-15.

[16] Melnyk M., Korcelli-Olejniczak E., Chorna N., Popadynets N. (2018). Development of regional IT clusters in Ukraine: Institutional and investment dimensions. Economic Annals - XXI, vol. 173, no. 910, pp. 19-25. DOI: 10.21003/ea.V173-03.

[17] Nadeem M., Dumay J, Massaro M. (2019). If you can measure it, you can manage it: A case of intellectual capital. Australian Accounting Review, vol. 29, no. 2 (June), pp. 395-407. DOI http://dx.doi.org/10.2139/ssrn.3032145.

[18] Nambisan S., Wright M., Feldman M. (2019). The digital transformation of innovation and entrepreneurship: Progress, challenges and key themes. Research Policy, vol. 48, no. 8. DOI: 10.1016/j.respol.2019.03.018.

[19] Ravarini A., Locoro A., Martinez M. (2020). Digital transformation projects maturity and managerial competences: A model and its preliminary assessment. Lecture Notes in Information Systems and Organisation, vol. 33, pp. 261-272. DOI: 10.1007/9783-030-23665-6_19.

[20] Soetanto T., Liem P.F. (2019). Intellectual capital in Indonesia: Dynamic panel approach. Journal of Asia Business Studies, vol. 13, no. 2, pp. 240-262. DOI: https://doi.org/10.1108/JABS-02-2018-0059.

[21] Subramanian A.M., van de Vrande V. (2019). The role of intellectual capital in new product development: Can it become a liability? Journal of Operations 
Management, vol. 65, no. 6, pp. 517-535. DOI: https://doi.org/10.1002/joom.1045.

[22] Sung R.C.W., Ritchie J.M., Lim T., Liu Y., Kosmadoudi Z. (2012). The automated generation of engineering knowledge using a digital engineering tool: An industrial evaluation case study. International Journal of Innovation and Technology Management, vol. 9, no. 6. DOI: 10.1142/S0219877012710010.

[23] Tlesova A., Mergaliyeva L., Sultanguzhiyeva A., Sharafutdinova A. (2018). Improvement of innovative economic policy. Journal of Applied Economic Sciences, vol. 13, no. 6, pp. 1654-1667.

[24] Tortorella G.L., Cawley Vergara A.M., GarzaReyes J.A., Sawhney R. (2020). Organizational learning paths based upon industry 4.0 adoption: An empirical study with Brazilian manufacturers. International Journal of Production Economics, vol. 219, pp. 284294. DOI: 10.1016/j.ijpe.2019.06.023.

[25] Urbinati A., Chiaroni D., Chiesa V., Frattini F. (2019). The role of business model design in the diffusion of innovations: An analysis of a sample of unicorn-tech companies. International Journal of Innovation and Technology Management, vol. 16, no. 1, pp. 235-245.

[26] Zhang M., Lettice F., Pawar K. (2019). Effects of intellectual capital and university knowledge in indigenous innovation: evidence from Indian SMEs. Production Planning and Control, vol. 30, no. 10-12, pp. 799-812. DOI: https://doi.org/10.1080/09537287 .2019 .1582090 . 